\title{
DIREITO FUNDAMENTAL DIFUSO DE ACESSO DAS PESSOAS COM DEFICIÊNCIA A ESPAÇOS URBANOS E SUA TUTELA JURÍDICA COLETIVA
}

\section{DIFFUSED FUNDAMENTAL RIGHT OF ACCESS OF PEOPLE WITH DISABILITIES TO URBAN SPACES AND THEIR COLLECTIVE LEGAL GUARDIANSHIP}

FLÁVIA PIVA ALMEIDA LEITE

Doutora em Direito Urbanístico pela Pontifícia Universidade Católica - PUC - São Paulo/SP, Mestre em Direito Constitucional pela Instituição Toledo de Ensino - ITE Bauru/SP, Pós-graduada em Gerente de Cidades pela Fundação Armando Álvares Penteado - FAAP - São Paulo/SP. Docente da UNESP - Universidade Estadual Paulista "Julio de Mesquita Filho", Faculdade de Arquitetura, Artes e Comunicação Campus Bauru. Docente permanente do Programa de Pós-Graduação em Direito da UNESP- Franca. Avaliadora do CONPEDI.

RUI CARVALHO PIVA

Pós-Doutor em Direito pela Universidade de Messina - Itália. Doutor, Mestre e Especialista em Direito pela PUC/SP. Bacharel em Direito pela Instituição Toledo de Ensino - 1ํㅡㄴ a $4^{\circ}$ anos na Faculdade de Direito da USP em São Paulo. Bacharel em Psicologia Clínica pelo Centro de Ensino Unificado de Brasília - $1^{\circ}$ e $2^{\circ}$ anos na UNESP em Bauru. Professor do Corpo Docente Permanente dos Cursos de Doutorado, Mestrado e Graduação do Centro Universitário de Bauru, mantido pela Instituição Toledo de Ensino. Líder do Grupo de Pesquisa "Processos Coletivos" do Centro Universitário de Bauru, mantido pela Instituição Toledo de Ensino. Avaliador do CONPEDI. 


\section{RESUMO}

Esse artigo jurídico trata de um dos temas mais relevantes do momento das pessoas com deficiência e de suas famílias que vivem nos espaços urbanos brasileiros. $O$ acesso das pessoas com deficiência aos espaços urbanos é um direito com expresso reconhecimento legal e esse direito vem sendo considerado como caminho indispensável para a inclusão social dessas pessoas. Acesso e inclusão, que tiveram suas trajetórias de consideração e inclusão na legislação da Organização das Nações Unidas e do Brasil, sempre foram considerados sob a ótica de direitos individuais, sendo certo que a busca de suas efetivações ocorriam por meio dos instrumentos processuais igualmente individuais, ou seja, ações civis para cumprimento de obrigação de fazer e para apuração de danos materiais e morais provocados por entidades públicas e particulares. Uma nova abordagem jurídica para esta situação de descumprimento do comando legal permitiu a identificação do direito de acesso das pessoas com deficiência aos espaços urbanos como sendo um direito fundamental, porque as previsões que o asseguram preservam a dignidade dessas pessoas e o direito à vida digna é um direito fundamental, e permitiu também a sua identificação como um direito difuso, por ser um direito transindividual, de natureza indivisível, cujos titulares são pessoas indeterminadas e ligadas por circunstância de fato. Sendo assim, a sua tutela jurídicapode ser efetivada por meio da poderosa ação civil pública, o que representa uma ampliação respeitável das possibilidades de acesso e inclusão para as pessoas com deficiência aos espaços urbanos.

PALAVRAS-CHAVE: Acessibilidade; Espaços urbanos; Direito Fundamental Difuso; Pessoa com deficiência; Tutela Jurídica coletiva.

\section{ABSTRACT}

This legal article deals with one of the most relevant issues of the moment for people with disabilities and their families living in Brazilian urban spaces. The access of people with disabilities to urban spaces is a right with express legal recognition and this right is being considered as an indispensable way for the social inclusion of these people. Access and inclusion, which had their consideration and inclusion trajectories in the 
legislation of the United Nations and Brazil, they have always been considered from the perspective of individual rights, being certain that the search for its effectiveness occurred through the equally individual procedural instruments, that is, civil actions to fulfill the obligation to do and to ascertain material and moral damages caused by public and private entities. A new legal approach at this situation of non-compliance with the legal command identified the right of access of disabled people to the urban areas as a fundamental right, because the predictions that ensure preserve the dignity of such persons and the right to decent life is a fundamental right, and also allowed its identification as a diffuse right, because it is a transindividual right, of an indivisible nature, whose holders are indeterminate persons and connected by de factual circumstance. Thus, its legal protection can be effected through the powerful public civil action, which represents a respectable increase in the possibilities of access and inclusion for people with disabilities in urban spaces.

KEYWORDS: Accessibility; Urban spaces; Diffuse Fundamental right; Disabled person; Collective legal guardianship.

\section{INTRODUÇÃO}

O objetivo do presente trabalho é a exposição sistemática da trajetória legislativa que assegurou, ou, pelo menos, avançou significativamente no sentido de assegurar acessibilidade das pessoas com deficiência aos espaços urbanos no território brasileiro e, com isso, proporcionar a inclusão das mesmas.

A sua elaboração, um dos ônus docentes destinados a cumprir algumas das etapas anuais de atualização profissional,proporcionou um especial bem estar intelectual e humano, na medida em que foi necessário buscar e apresentar argumentos, fatos e fundamentos jurídicos, sociais e históricos capazes de assegurar mais uma especial proteção aos seres humanos com deficiência, ou seja, a tutela jurídica coletiva de seu direito de acesso aos espaços urbanos por meio da ação civil pública. 
Aqui, esse direito foi identificado como fundamental difuso, vale dizer, um direito constitucional metaindividual, indivisível, cujos titulares, indeterminados no momento da busca do amparo judicial, estarão ligados pela ampla circunstância de serem brasileiros e estrangeiros residentes no Brasil e serão determinados por ocasião da outorga do direito individual homogêneo que lhes assegurará o quanto obtido na decisão judicial proferida na correspondente ação civil pública.

Para tanto, foram expostas inicialmente, no presente trabalho breves e precisas considerações sobre a normatização da acessibilidade no Brasil, aí incluída a Lei Brasileira de inclusão da pessoa com deficiência, considerações essas complementadas com informações sobre os progressos dessa proteção ao acesso no âmbito internacional, em especial no âmbito da Organização das Nações Unidas, e com o esclarecimento do significado das expressões "inclusão" e "acessibilidade".

$\mathrm{Na}$ sequência apresentamos dois importantes aspectos do mais poderoso instrumento processual de efetivação de direitos difusos e coletivos, que é a ação civil pública. Lá, foram registradas informações sobre a origem e sobre os objetos da referida ação.

De seus aspectos históricos, ressalte-se a existência de conflitos coletivos de interesses já na Inglaterra dos Séculos XVII e XVIII.

A passagem desses conflitos pela China e pela Rússia, agora vinculados aos movimentos socialistas, traz para o presente trabalho as indispensáveis visões Políticas e Ideológicas que se aproximam e sempre se fazem presentes na evolução do Direito.

Ainda sobre a origem da ação civil pública, é de todo interessante conhecer o acabamento jurídico de qualidade que a ação civil pública recebeu nos Estados Unidos, em especial o fato de que os titulares do direito coletivo tutelado pela referida ação não mais eram pessoas determinadas, pois passaram a ser, como são até o momento, pessoas indeterminadas.

A questão central do objetivo do presente trabalho foi minuciosamente apresentada no Capítulo 3. Nele, foi justificadaa natureza jurídica fundamental difusa do direito de acesso das pessoas com deficiência aos espaços urbanos e, como consequência direta a possibilidade de sua tutela judicial por meio da ação civil pública. 
A metodologia utilizada foi a pesquisa em fontes doutrinárias e legais.

\section{BREVES CONSIDERAÇÕES SOBRENORMATIZAÇÃO DA ACESSIBILIDADE AOS ESPAÇOS URBANOS NO BRASIL, NA ESTEIRA DAS RECOMENDAÇÕES DA ORGANIZAÇÃO DAS NAÇÕES UNIDAS}

Considerando que, segundo dados estatísticos do Censo- IBGE de 2010, cerca de mais de $80 \%$ da população brasileira vive em cidades, não há a menor dúvida que o Brasil é um país urbano. E, segundo dados do mesmo órgão cerca de $45,6 \%$ de pessoas possuem algum tipo de deficiência (Brasil, 2015) ${ }^{1}$. Este número corresponde a 23,9\% da população brasileira (IBGE, 2019). Todas essas pessoas têm o mesmo direito à inclusão do que as que não apresentam deficiência.

Todavia, as pessoas que não possuem deficiência, ou não lidam com a questão, não costumam perceber as inúmeras situações discriminatórias que as pessoas com deficiência sofrem com um projeto negligente ou inadequado.

No início de um projeto de construção de um ambiente, as pessoas em cadeiras de rodas, por exemplo, são muitas vezes excluídas pela inexistência de calçadas rebaixadas na maior parte das vias de circulação. A falta de acessibilidade nos espaços públicos, nas vias públicas, no mobiliário urbano, nos transportes, nos meios de comunicação, na informação e tecnologias e sinalizações, faz com que essas pessoas fiquem confinadas em suas casas ou em clínicas.

Sem os espaços adaptados, não se tem acessibilidade, e, sem esta, não há direitos iguais, não há inclusão social.

Já está comprovado em vários estudos e experimentações que a inclusão é um processo de transformação que se manifesta na mudança de atitudes, do comportamento, da administração, do atendimento da organização físico-espacial ao

\footnotetext{
1 Segundo art. 2 da Lei n. 13.146/2015 (Lei Brasileira de Inclusão da Pessoa com Deficiência - Estatuto da Pessoa com Deficiência) considera-se "pessoa com deficiência aquela que tem impedimento de longo prazo, de natureza física, mental, intelectual ou sensorial, o qual, em interação com uma ou mais barreiras, pode obstruir sua participação plena e efetiva na sociedade, em igualdade de condições com as demais pessoas."
} 
longo do tempo. Inclusão manifesta-se, então, por meio da acessibilidade. (GUIMARÃES,2019).

Inclusão, pois, decorre dessa circunstância humana inarredável: do latim inclusio, inclusionis significa "a ação ou efeito de incluir. E includere (incluir): compreender ou abranger; inserir; envolver; fazer parte" (HABERMAS,2002, pp. 185 e seg). A mesma palavra encontra-se implícita na Constituição Federal, quando o art. 5o, caput, estabelece: "Todos são iguais perante a Lei, sem distinção de qualquer natureza, (...) garantindo-se a inviolabilidade do direito à vida, à liberdade, à igualdade, à segurança e à propriedade". Nesse sentido também o que dispõe o art. $3^{\circ}$, IV, do texto constitucional, quando estatui os objetivos fundamentais da República Federativa do Brasil: "promover o bem de todos, sem preconceitos de origem, raça, sexo, cor, idade e quaisquer outras formas de discriminação".

O termo acessibilidade indica a condição de livre acesso, de possibilidade. Falar em acessibilidade, em termos gerais, segundo José Antônio Lanchotti, é "compreender a possibilidade de acesso, da aproximação, da utilização, do manuseio de qualquer objeto, local, ou condição e, tudo isso, deve ser oferecido com facilidade, não exigindo um esforço excessivo". (LANCHOTTI, 2005, p. 28)

Por ser um processo de transformação do ambiente que se desenvolve a partir do reconhecimento social de que a deficiência é resultante do desajuste entre as características físicas das pessoas e as condições onde elas atuam, a acessibilidade passa a ser retomada como um tema de grande importância no planejamento urbano.

Mesmo diante desse modelo inaugurado pela na nova ordem constitucional, o que vemos ainda é um sistema de discriminação em relação às pessoas que não conseguem usufruir de muitos direitos assegurados no ordenamento constitucional e, dentre esses, o direito de se locomoverem pelos espaços públicos de sua cidade de forma plena e com autonomia. Para que esse direito ocorra, faz-se necessário que os gestores públicos municipais cumpram as normas de acessibilidade nos espaços públicos da cidade. Portanto, não se pode falar em inclusão social sem uma cidade acessível.

A questão da acessibilidade não é um tema tão recente.

Tal como acontece em muitos países, no Brasil teve início em 1981, quando foi declarado o Ano Internacional dos Portadores de Deficiência pelas Nações Unidas. 
No ano de 1982, a mesma Organização aprovou o Programa de Ação Mundial para Pessoas com Deficiência, ressaltando o direito dessas pessoas com deficiência a terem as mesmas oportunidades que os demais cidadãos e a desfrutarem, em condições de igualdade, de melhorias nas condições de vida resultantes do desenvolvimento econômico e social.

Dentro desse contexto, o Brasil publicou a primeira norma técnica sobre o tema - a NBR 9050/1985 - Adequação das Edificações e do Mobiliário Urbano à Pessoa Deficiente, elaborada pela comissão de estudos do Comitê Brasileiro da Construção Civil, da Associação Brasileira de Normas Técnicas.

Após três anos, foi promulgada a Constituição Federal de 1988, que disciplinou a acessibilidade, quando assegurou, no artigo 227 , $\S 2^{\circ}$, que a Lei deveria dispor sobre normas de construção dos logradouros e dos edifícios de uso público e de fabricação de veículos de transporte coletivo, a fim de garantir o acesso adequado às pessoas com deficiência, e, no artigo 244 complementou a citada norma, acrescentando que a Lei deveria dispor sobre a adaptação dos logradouros, dos edifícios de uso público e dos veículos de transporte coletivo atualmente existentes, a fim de garantir acesso adequado às pessoas portadoras de deficiência, conforme 0 disposto no artigo 227, $\S 2^{\circ}$ ".

Atendendo a tal comando, foi editada a Lei $n^{\circ} 7.85389$, que dispôs sobre 0 apoio às pessoas portadoras de deficiência, sua integração social, sobre a CORDE (Coordenadoria Nacional para Integração da Pessoa com Deficiência), instituiu a tutela jurisdicional de interesses coletivos ou difusos dessas pessoas, disciplinou a atuação do Ministério Público, definiu crimes, e de outras providências.

Em seu artigo $2^{\circ}$, já assegurava que os órgãos e entidades da Administração direta e indireta deveriam dispensar tratamento prioritário e adequado às pessoas com deficiência, determinando, na área das edificações, a adoção e a efetiva execução de normas que garantam a funcionalidade das edificações e vias públicas, que evitem ou removam os óbices às pessoas com deficiência, permitindo o acesso destas a edifícios, a logradouros e a meios de transportes.

O Decreto $n^{\circ} 3.29899$ que regulamentou a Lei $n^{\circ} 7.85389$ trouxe como um dos objetivos da Política Nacional para Integração da Pessoa Portadora de Deficiência o acesso, o ingresso e a permanência delas em todos os serviços oferecidos à 
comunidade, estabelecendo em seu artigo $2^{\circ}$, parágrafo único, que os órgãos e entidades da administração direta e indireta devem dispensar tratamento prioritário e adequado para viabilizar medidas em diversas áreas, dentre as quais, a adoção e execução de normas que garantam a funcionalidade das edificações e vias públicas, que evitem ou removam os óbices às pessoas portadoras de deficiência e que permitam o acesso destas aos edifícios, logradouros e meios de transporte.

A acessibilidade foi novamente tratada pela Lei $n^{\circ} 10.048 / 00$ que assegurou tratamento prioritário às pessoas com deficiência, idosos, às gestantes, às lactantes e às pessoas acompanhadas por crianças de colo. Essa lei obrigou as repartições públicas, empresas concessionárias de serviço público e instituições financeiras a dispensar tratamento prioritário, por meio de serviços individualizados a essas pessoas, bem como a reservar assentos nos transportes coletivos; estabeleceu ainda que compete às autoridades adotarem normas de construção e licenciamento para garantir acessibilidade em logradouros e sanitários públicos, bem como em edifícios de uso público e também, a acessibilidade nos meios de transportes.

A Lei $n^{\circ} 10.098 / 00$ estabeleceu normas gerais e critérios básicos para promoção da acessibilidade das pessoas com deficiência ou com mobilidade reduzida, nas edificações públicas ou privadas, no espaço público, logradouros e seu mobiliário, nas comunicações e sinalização entre outros.

O objetivo desta lei será alcançado quando forem suprimidas as barreiras e obstáculos nas vias e espaços públicos, no mobiliário urbano, na construção e reforma de edifícios e nos meios de transporte e de comunicação. Para os fins da lei foram estabelecidas várias definições em seu capítulo primeiro, dentre as quais, o que é acessibilidade, barreiras, elementos de urbanização, mobiliário urbano, ajuda técnica e, de forma simplificada, a definição de pessoa com deficiência.

Após quatro anos, foi publicado o Decreto $n^{\circ} 5.296$, de 02 de dezembro de 2004 que regulamentou as Leis $n^{\circ} 10.04800$, que dá prioridade de atendimento às pessoas que especifica e, a de $n^{\circ} 10.09800$, que estabelece normas gerais e critérios básicos para a promoção de acessibilidade das pessoas portadoras de deficiência ou com mobilidade reduzida. Ficam sujeitos ao cumprimento deste Decreto, a aprovação de projeto de natureza arquitetônica e urbanística, de comunicação e informação, de transporte coletivo e a execução de qualquer tipo de obra, de destinação pública ou 
coletiva; a outorga de permissão, autorização ou habilitação de qualquer natureza; a aprovação de financiamento de projetos com a utilização de recursos públicos, por meio de convênio, acordo, ajuste, contrato ou similar; e a concessão de aval da União na obtenção de empréstimos e financiamentos internacionais por entes públicos ou privados.

A luta pela inclusão dessas pessoas em todos os segmentos da sociedade não parou. A ONU, preocupada com as sucessivas violações dos direitos humanos das pessoas com deficiência no mundo inteiro, conclui que esse grupo demandava uma atitude institucional da comunidade internacional, e, em 30 de março de 2007, em sua sede em Nova Iorque, assinou a Convenção sobre os Direitos das Pessoas com Deficiência e o seu Protocolo Facultativo. Como mencionamos anteriormente, a Convenção sobre os Direitos das Pessoas com Deficiência e seu Protocolo Facultativo passou a ser o primeiro Tratado Internacional a ingressar na nossa ordem jurídica interna com status de equivalência constitucional, por ter sido aprovado nos exatos termos da regra imposta pelo $\S 3^{\circ}$ do art. $5^{\circ}$ da Constituição Federal. A principal contribuição desta Convenção é a positivação da mudança de paradigma da visão da deficiência no mundo, que passa do modelo médico, no qual a deficiência é tratada como um problema de saúde, para o modelo social dos direitos humanos, no qual a deficiência é resultante de uma equação que tem duas variáveis, quais sejam as limitações funcionais do corpo humano e as barreiras impostas pelo ambiente exclusivo ao indivíduo.

A Convenção, ao ter reconhecido o modelo social como o mais novo paradigma para conceituar as pessoas com deficiência, embasou também a consolidação da acessibilidade positivada como princípio fundamental para que esse segmento concretize seus direitos fundamentais em todos os aspectos de suas vidas. Assim, a Convenção reconheceu expressamente à importância da acessibilidade aos meios físico, social, econômico e cultural, à saúde, à educação, e à informação e comunicação, para possibilitar às pessoas com deficiência o pleno gozo de todos os direitos humanos e liberdades fundamentais. E seu artigo $3^{\circ}$, juntamente com o respeito à dignidade, a autonomia individual, aliada a liberdade de fazer suas próprias escolhas, a independência, a não-discriminação, a plena e efetiva participação e inclusão, o respeito à diferença, a igualdade de oportunidades, a acessibilidade foi 
elencada como um dos princípios gerais que deverão nortear a vida das pessoas com deficiências. $^{2}$

Assim, para que a pessoa com deficiência exerça de forma efetiva o direito à acessibilidade, a Convenção determinou também em seu artigo $9^{\circ}$, que os Estados estarão obrigados a tomar medidas apropriadas para assegurar a sua efetivação, em igualdade de oportunidades com as demais pessoas, ao meio físico, ao transporte, à informação e comunicação, bem como a outros serviços e instalações abertos ao público ou de uso público, tanto na zona urbana como na rural.Mais adiante, aponta que as medidas destinadas à implementação da acessibilidade deverão incluir a identificação e eliminação de obstáculos e barreiras, expressamente determinando o dever de observância de normas de acessibilidade em edifícios, rodovias, meios de transporte e outras instalações internas e externas, inclusive escolas, residências, instalações médicas e local de trabalho. Também se exige a acessibilidade no que diz respeito a informações, comunicações e outros serviços, inclusive serviços eletrônicos e serviços de emergência.

Na tentativa de cumprir o objetivo da acessibilidade acima mencionado, trouxe a Lei n. 13.146/2015, em seu art. 3ํㅡ, I, o que considera acessibilidade: Possibilidade e condição de alcance para utilização, com segurança e autonomia, de espaços, mobiliários, equipamentos urbanos, edificações, transportes, informação e comunicação, inclusive seus sistemas e tecnologias, bem como de outros serviços e instalações abertos ao público, de uso público ou privados de uso coletivo, tanto na zona urbana como na rural, por pessoa com deficiência ou com mobilidade reduzida.

E, abrindo o Capítulo referente à acessibilidade, o art. 53 da Lei $n$. 13.146/2015 asseverou que a acessibilidade é o direito que garante à pessoa com deficiência ou com mobilidade reduzida viver de forma independente e exercer seus direitos de cidadania e de participação social.Em seu artigo 55 , determinou que a concepção e a implantação de projetos que tratem do meio físico, de transporte, de

\footnotetext{
2 "Artigo $3^{\circ}$ - Princípios gerais. Os princípios da presente Convenção são: a) O respeito pela dignidade inerente, a autonomia individual, inclusive a liberdade de fazer as próprias escolhas, e a independência das pessoas; b) A não discriminação; c) A plena e efetiva participação e inclusão na sociedade; d) $O$ respeito pela diferença e pela aceitação das pessoas com deficiência como parte da diversidade humana e da humanidade; e) A igualdade de oportunidades; f) A acessibilidade; g) A igualdade entre o homem e a mulher; $h$ ) O respeito pelo desenvolvimento das capacidades das crianças com deficiência e pelo direito das crianças com deficiência de preservar sua identidade".
} 
informação e comunicação, inclusive de sistemas e tecnologias da informação e comunicação, bem como de outros serviços, equipamentos e instalações abertos ao público, de uso público ou privado de uso coletivo, seja na zona urbana ou na zona rural, deverão atender aos princípios do desenho universal.

A expressão desenho universal ou universal designer foi cunhada pelo arquiteto Ron Mace, que articulou e influenciou uma mudança nos paradigmas dos projetos de arquitetura e design. (CAMBIAGHI, 2007, p. 71) Segundo ele, o desenho universal é utilizado para descrever o conceito de projetar e construir produtos ou ambientes para ser utilizável, na maior medida possível, por todos. (MACE, 2015). O objetivo principal dessa nova concepção, segundo assevera José AntonioLanchotti, é o de "simplificar as ações do dia a dia de todas as pessoas, produzindo ambientes, objetos e comunicações que possam ser utilizados por todas as pessoas sem precisar de custos extras com adaptações ou adequações, beneficiando usuários de várias idades e habilidades". (LANCHOTTI, 2005, p. 105)

A definição de desenho universal veio expressa na NBR 9050/2004 da ABNT e no art. $8^{\circ}$, IX, do Decreto n. 5.296/2004. Encontramos atualmente a definição de desenho universal na Lei n. 13.146/2015, em seu art. $3^{\circ}$, II, como sendo a concepção de produtos, ambientes, programas e serviços a serem usados por todas as pessoas, sem necessidade de adaptação ou de projeto específico, incluindo os recursos de tecnologia assistida.

Por sua vez, o artigo 54 da LBI define a abrangência de aplicabilidade da acessibilidade ao estabelecer que todos os projetos e as obras com destinação públicaou coletiva, que sejam de natureza arquitetônica, urbanística, de comunicação e informação ou a fabricação de veículos de transporte e a prestação do respectivo serviço, assim como autorizações, outorgas, concessões, financiamentos, convênios, bem com obtenção de empréstimo e de financiamentos internacionais por entes públicos ou privados com aval da União, que tenham interação com a matéria regulamentada, devem atender ao disposto nesta lei.

O artigo 55 da Lei n. 13.146/2015 determina que toda a concepção e a implantação de projetos que tratem do meio físico, de transporte, de informação e comunicação, inclusive de sistemas e tecnologias da informação e comunicação, e de outros serviços, equipamentos e instalações abertos ao público, de uso público ou 
privado de uso coletivo, tanto na zona urbana como na rural, devem atender aos princípios do desenho universal, tendo como referência as normas de acessibilidade.

No artigo 56, o Estatuto determina que a construção, reforma, ampliação ou mudança de uso de edificações abertas ao público, de uso público ou privadas de uso coletivo, deverão ser executadas de modo a serem acessíveis, sendo que, nos termos do artigo 57, as edificações públicas e privadas de uso coletivo já existentes deverão garantir acessibilidade à pessoa com deficiência em todas as suas dependências e serviços, nos termos das normas de acessibilidade vigentes. O mesmo vale para os edifícios de uso privado multifamiliar, conforme o artigo 58 do Estatuto.

Cabe registrar que, recentemente, o então Presidente Michel Temer mandou publicar o Decreto de n. 9.296, de 01 de março de 2018 que regulamentou o artigo 45 da Lei Brasileira de Inclusão da Pessoa com Deficiência - Estatuto da Pessoa com Deficiência. Referido Decreto veio para regulamentar a acessibilidade nos hotéis, pousadas e estruturas similares e, para tanto, assegura que a "concepção e a implementação dos projetos arquitetônicos de hotéis, pousadas e estruturas similares deverão atender aos princípios do desenho universal e ter como referências básicas as normas técnicas de acessibilidade da Associação Brasileira de Normas Técnicas (ABNT)...". (art. 1ㅇ).

Em síntese, determina o Estatuto, à luz do que vem disposto na Constituição, especialmente com a alteração promovida pela Convenção da ONU, que um espaço será acessível (ambiente urbano/rural ou edificação) quando todos puderem ingressar, circular e utilizar todos os ambientes e não apenas parte deles. Pois, a essência do desenho universal está no propósito de estabelecer acessibilidade integrada a todos, sejam ou não pessoas com deficiência. $O$ termo acessibilidade representa uma meta de ampla inclusão, não um eufemismo. (CAMBIAGHI, 2007, p. 73)

Sendo assim, é inconcebível, nos dias atuais, que obras continuem sendo construídas ou reformadas ou projetos elaborados sem contemplar os princípios do desenho universal e, consequentemente, sem assegurar a acessibilidade. Portanto, toda e qualquer construção, reforma ou ampliação tanto públicas e quanto privadas de uso coletivo, como vias e espaços públicos, deverão estar acessíveis.

3 AÇÃO CIVIL PÚBLICA: ORIGEM E OBJETOS 
O Bill of Peace, sistema jurisdicional que admitia litisconsórcio voluntário em ações destinadas a dirimir, por intermédio dos Tribunais da Equidade, conflitos de muitas pessoas determinadas que pleiteassem interesses comuns, foi instalado na Inglaterra, nos séculos XVII e XVIII.

Na China, em 1911, e na Rússia, em 1917, as revoluções socialistas trouxeram para o cenário dos conflitos interesses de grupos de pessoas, envolvendo questões políticas, econômicas e sociais.

Tanto na Inglaterra como na China, esses conflitos eram vistos como conflitos de interesses coletivos de pessoas determinadas.

Nos Estados Unidos, em 1938, foram disciplinadas três espécies de class actions para dirimir conflitos coletivos de pessoas representadas por um único integrante da classe, ou seja, as espécies true, hybride spurious. (GRINOVER, 2007, p. 875)

Em 1996, ainda nos Estados Unidos, a regra 23 da Federal Rules, que alterou a Lei de 1938, estabeleceu três espécies de class actions, sendo duas obrigatórias e a terceira delas não obrigatória.

Foi na Itália, porém, na década iniciada em 1970, que se desenvolveu e ganhou destaque o estudo dos interessesdifusos, identificados pela indeterminação de seus titulares e indivisibilidade de seu objeto.

Era uma resposta dos pensadores do direito em face das modificações das relações sociais, políticas e econômicas na sociedade e do surgimento de intensos conflitos de massa, nos quais os interesses manifestados não mais se identificavam com interesses públicos nem privados, até então os únicos reconhecidos pela doutrina jurídica.

A intensidade com que se manifestavam esses interesses difusos proporcionou o surgimento, ainda que forçado, de um modo diferente de administrar o Estado.

A defesa da soberania do povo não mais era reconhecida como tarefa exclusiva do Poder Público, na medida em que grupos representativos da sociedade assumiam o comando de uma espécie de soberania social em face das demandas em massa. 
A intensa ingerência do pensamento desses grupos sociais na forma de administrar o Estado exigiu que se criasse, no sistema jurídico, meios de tutelar essas manifestações.

Havia necessidade de renovação das ideias e isso ocorreu por meio da utilização de um processo no qual essas ideias foram incorporadas.

Aqui no Brasil, a pregação doutrinária dos juristas italianos repercutiu.

A defesa judicial do direito difuso ao meio ambiente ecologicamente equilibrado foi prevista no $\S 11^{\circ}$ do artigo 14 da Lei 6.938 de 31 de agosto de 1981, também conhecida como Lei da Política Nacional do Meio Ambiente, onde constou a obrigação do poluidor de indenizar ou reparar o dano causado ao meio ambiente e a terceiros afetados por sua atividade, independentemente da existência de culpa, ficando o Ministério Público legitimado para propor a correspondente ação de responsabilidade civil e criminal.

A mencionada Lei $6.939 / 81$ teve seus procedimentos processuais disciplinados pela Lei 7.347/85, a denominada Lei da Ação Civil Pública, cujo artigo $1^{\circ}$ estabeleceu, em sua redação original, que as ações de responsabilidade por danos morais e patrimoniais causados ao meio ambiente, ao consumidor e a bens e direitos de valor artístico, estético, histórico, turístico e paisagístico seriam regidos por suas disposições.

Em 1990, cinco anos após o início de vigência da Lei 7.347, a Lei 8.078, que ficou conhecida como Código Brasileiro de Defesa do Consumidor, em seu artigo 110, ampliou o alcance dos objetos da ação civil pública ao acrescentar o inciso IV ao artigo $1^{\circ}$ da Lei $7.347 / 85$, de tal modo que as ações de responsabilidade por danos morais e patrimoniais causados a qualquer outro direito difuso ou coletivo, além daqueles já previstos na redação original da lei, passaram a ser por ela regidos.

Posteriormente, agora no ano de 2001, a ação civil pública, por expressa disposição contida no artigo 6 da Medida Provisória 2180-35, passou a ser também o instrumento para apurar a responsabilidade por danos morais e patrimoniais causados por infração da ordem econômica e da economia popular, conforme disposto no inciso $V$ acrescentado ao artigo $1^{\circ}$ da Lei $7.347 / 85$, bem como da ordem urbanística, previsto no inciso $\mathrm{VI}$ acrescentado ao mesmo artigo $1^{\circ}$.

$\mathrm{O}$ artigo 117 da Lei 12.529/2011 determinou que o inciso $V$ do artigo $1^{\circ}$ da Lei 
7.347/85 passasse a se referir somente às infrações da ordem econômica.

No ano de 2014, a Lei 12.966 determinou a inclusão, no artigo $1^{\circ}$ da Lei $7.347 / 85$, do inciso VII, de tal modo que a ação civil pública passou a ser o instrumento processual de apuração de danos morais e patrimoniais causados à honra e à dignidade de grupos raciais, étnicos ou religiosos.

Finalmente, por expressa disposição da Lei 13.004/2014, a ação civil pública passou a ser o instrumento processual de apuração de danos morais e patrimoniais causados ao patrimônio público e social.

Em suma, a apuração de danos morais e patrimoniais promovida por intermédio da ação civil pública disciplinada pela Lei $7.347 / 85$, vale dizer, os objetos da ação civil pública na legislação brasileira referem-se, atualmente, aos seguintes direitos difusos ou coletivos:

- Direito decorrente de infração praticada contra o meio-ambiente ecologicamente equilibrado.

- Direito decorrente de infração praticada contra o consumidor.

- Direito decorrente de infração praticada contra bens e direitos de valor artístico, estético, histórico, turístico e paisagístico.

- Direito decorrente de infração praticada contra qualquer outro interesse difuso ou coletivo.

- Direito decorrente de infração praticada contra a ordem econômica.

- Direito decorrente de infração praticada contra a ordem urbanística.

- Direito decorrente de infração praticada contra a honra e a dignidade de grupos raciais, étnicos ou religiosos.

- Direito decorrente de infração praticada contra o patrimônio público e social

Aqui, para uma boa e refinada compreensão, a lição de Rodolfo de Camargo Mancuso (MANCUSO, 2011, p. 32-33), auxiliado pelo sempre Professor Moacyr Amaral Santos:

O objeto, nas ações civis públicas, é exteriorizado através do pedido, que permite múltiplas formulações: simples, cumulado, sucessivo, alternativo, eventual (CPC, art. 286 e ss.). Também relevante é a distinção entre pedidos imediato e mediato: na lição de Moacyr Amaral Santos, 'o pedido imediato consiste na providência jurisdicional solicitada: sentença condenatória, declaratória, constitutiva ou mesmo providência executiva, cautelar ou preventiva. O pedido mediato é a utilidade que se quer alcançar pela 
sentença, ou providência jurisdicional, isto é, o bem material ou imaterial pretendido pelo autor.

Devemos atentar para o fato de que a especificação de seis dos objetos acima relacionados poderá significar um aceitável fator de identificação de hipóteses de danos morais e patrimoniais capazes de fundamentar o cabimento de uma ação civil pública, mas uma de suas previsões, aquela contida no inciso IV do artigo 1ํㅜ , que se refere a qualquer outro interesse difuso e coletivo, representa uma verdadeira cláusula de generalização de seus objetos.

Paralelamente à generalização, confira abaixo uma restrição aos seus objetos.

A já mencionada Medida Provisória 2.180-35/2001, em previsão contida em seu artigo 6을 acrescentou um parágrafo único ao artigo $1^{\circ}$ da Lei $7.347 / 85$, determinando o não cabimento da ação civil pública para pleitear pretensões que envolvam tributos, contribuições previdenciárias, o Fundo de Garantia do Tempo de Serviço - FGTS ou outros fundos de natureza institucional cujos beneficiários podem ser individualmente determinados.

Não obstante a exclusão mencionada, que é de longo alcance em face da vocação intervencionista do Estado Brasileiro na economia das pessoas, a Lei $7.347 / 85$ trouxe conflitos sociais de grande abrangência e de forte peso político para a apreciação do Poder Judiciário por meio de ações coletivas que atraíram agentes até então desconhecidos para a demanda e exigiu soluções que ainda não haviam sido enfrentadas, ou seja, decidir reclamações sobre a gestão de uma política pública.

Como disse Fiorillo:

Através do seu art. 83, o Código de Defesa do Consumidor estabeleceu a admissibilidade de todas as ações e providência capazes de propiciar adequadae efetiva tutela para a defesa dos interesses tutelados por ele, de forma que a Lei da Ação Civil Pública não mais estava limitada às hipóteses iniciais, à época de sua promulgação. (FIORILLO,2013, p. 696). 


\section{A NATUREZA JURÍDICA FUNDAMENTAL DIFUSA DO DIREITO DE ACESSO DAS PESSOAS COM DEFICIÊNCIA AOS ESPAÇOS URBANOS E SUA TUTELA JUDICIAL COLETIVA}

O pressuposto é no sentido de que esse direito das pessoas com deficiência é um direito fundamental e é também um direito difuso.

Vamos verificar se o pressuposto, como recurso de argumentação em pesquisa jurídica, está correto.

Por que podemos reconhecer o direito de acesso das pessoas com deficiência aos espaços urbanos como um DIREITO FUNDAMENTAL?

Porque as previsões que 0 asseguram preservam a dignidade dessas pessoas e o direito à vida digna é um direito fundamental, tão bem identificado por Luís Roberto Barroso no trecho de sua obra mencionada (BARROSO, 2013, p. 43), que segue transcrito:

A dignidade, portanto, é um princípio jurídico de status constitucional. Como valor e como princípio, a dignidade humana funciona tanto como justificação moral quanto como fundamento normativo para os direitos fundamentais. $\mathrm{Na}$ verdade, ela constitui parte do conteúdo dos direitos fundamentais.

Em obra de reconhecida importância jurídica, Rogério, Francislaine e Jurandir afirmam: "Isso significa afirmar que a Magna Carta protege os direitos fundamentais de duas formas, uma protegendo o cidadão frente ao Estado e outra, através do Estado" (BRAGA; STRASSER; SANTOS, 2015, p. 223).

Por que podemos reconhecer esse direito como um DIREITO DIFUSO?

Pelo o seguinte: no artigo 81, parágrafo único, inciso I da Lei 8.078/90, conhecida como Código Brasileiro de Defesa do Consumidor, o legislador brasileiro conceituou direitos difusos como sendo os transindividuais, de natureza indivisível, de que sejam titulares pessoas indeterminadas e ligadas por circunstâncias de fato.

Vamos conferir cada um dos elementos integrantes do conceito de direito difuso e conferir se o direito de acesso das pessoas com deficiência aos espaços urbanos caracteriza-se como DIFUSO.

Trata-se de um direito TRANSINDIVIDUAL? 
Sim, porque protege TODAS as pessoas com deficiência, sendo, pois, um direito metaindividual, mais do que individual, ou seja, transindividual.

Ou, como afirmou Rui Carvalho Piva em sua obra intitulada Bem Ambiental, referindo-se ao direito ao meio ambiente ecologicamente equilibrado, um bem jurídico igualmente difuso, como o direito das pessoas com deficiência a espaços urbanos:

Assim é porque o interesse difuso é metaindividual, é mais do que individual. $\mathrm{O}$ direito que o tutela não prevê titularidade individual e nem titularidade aberta, fato este que não permite apropriação exclusiva do bem que representa o seu objeto mediato. (PIVA, 2000, p. 40).

\section{É um direito INDIVISÍVEL?}

Sim, na medida em que as EMPRESAS e ÕRGÃOS PÚBLICOS que a ele estão obrigados não podem assegurar o acesso a pessoas com deficiência visual e deixar de assegurar a pessoas com deficiência auditiva, por exemplo.

Por se referir, essa indivisibilidade, a um bem jurídico representado pelo direito fundamental difuso de acesso das pessoas com deficiência aos espaços urbanos,

\section{Seus titulares são INDETERMINADOS?}

Sim, embora possam ser determináveis em algum momento. Por exemplo: as pessoas com deficiência do Município de Jaú, Estado de São Paulo.

Eles estão ligados por uma circunstância de fato?

Sim, pelo fato de serem brasileiros ou estrangeiros residentes no país, amparados pela proteção prevista no caput do artigo 5ำ da Constituição Federal Brasileira.

Verifica-se, pois, que o direito de acesso das pessoas com deficiência aos espaços urbanos É UM DIREITO DIFUSO.

Sendo um direito difuso, poderá ser tutelado coletivamente por meio de ação civil pública.

Confira:

Lei 7.347/1985 - Lei da Ação Civil Pública. Art. 1ํ. Regem-se pelas disposições desta Lei, sem prejuízo da ação popular, as ações de responsabilidade por danos morais e patrimoniais causados: [...] IV - a qualquer outro interesse difuso ou coletivo. [...] Art. 3‥ A ação civil pública 
poderá ter por objeto a condenação em dinheiro ou o cumprimento de obrigação de fazer ou não fazer.

Do art. $5^{\circ}$ da Lei da Ação Civil Pública consta a relação dos órgãos legitimados para propositura da mesma em defesa dos direitos difusos e coletivos.

No que se refere especificamente ao direito fundamental difuso de acesso das pessoas com deficiência aos espaços urbanos, confira abaixo, em trecho da obra de Rui Carvalho Piva,a importância da legitimação de órgãos da sociedade para sua tutela jurídica coletiva:

A evidente necessidade da preservação dos direitos difusos para a qualidade
de vidas das pessoas em sociedade, para a preservação de direitos
fundamentais a elas outorgados pela ordem constitucional, aliada à
desagregação de sua titularidade, que os deixa assim como se fossem
"órfãos", como se fossem "crianças sem pais", justifica a legitimação de
entidades da sociedade para defendê-los por meio da ação civil pública. (PIVA, 2016, p. 35).

\section{CONCLUSÃO}

Nesse espaço reservado para a conclusão, serão destacados, na mesma ordem em que foram incluídos no texto, os principais aspectos dos fatos, dos argumentos, das referências legislativas e das opiniões doutrinárias relativas à normatização da acessibilidade aos espaços urbanos no Brasil e à identificação do direito de acesso e do direito à inclusão como um direito tutelável judicialmente por meio da ação civil pública.

Esta opção tem a finalidade de proporcionar ao leitor a oportunidade de rever de maneira resumida as ideias gerais expostas ao longo do artigo, facilitando a elaboração de pensamentos favoráveis ou contrários ao reconhecimento da proposta doutrinária ora apresentada.

Nesse sentido, devemos ter presente que $24 \%$ da população brasileira possui algum grau de deficiência, segundo dados do IBGE de 2010, ressaltando que nessa porcentagem da população não estão incluídas as pessoas com mobilidade reduzida, como os idosos, as gestantes e outras. 
A falta de acessibilidade nos espaços públicos faz com que essas pessoas fiquem confinadas em suas casas ou em clínicas, distantes da inclusão social.

Vários estudos demonstram que a inclusão é um processo de transformação que se manifesta na mudança de atitudes, do comportamento da administração e do atendimento da organização físico-espacial ao longo do tempo. Inclusão manifestase, então, por meio da acessibilidade.

Para que o direito à inclusão se efetive, faz-se necessário que os gestores públicos municipais cumpram as normas de acessibilidade nos espaços públicos das cidades.

Com a entrada em vigor da Lei Brasileira de Inclusão da Pessoa com Deficiência, a Lei no 13.146, de 07 de julho de 2015, ou Estatuto da Pessoa com Deficiência, como é conhecida, reafirmou-se no plano infraconstitucional a Convenção Internacional sobre os Direitos das Pessoas com Deficiência, aprovada pela Assembleia Geral das Nações Unidas em 13 de dezembro de 2006, promulgada pelo Brasil em 25 de agosto de 2009 e, no que tange ao tema acessibilidade, ratificou e especificou direitos antes já presentes no ordenamento pátrio.

Não obstante, é inconcebível, nos dias atuais, que obras continuem sendo construídas ou reformadas ou projetos elaborados sem contemplar os princípios do desenho universal e, consequentemente, sem assegurar a acessibilidade.

Portanto, toda e qualquer construção, reforma ou ampliação, tanto públicas quanto privadas, de uso coletivo, como vias e espaços públicos, deverão estar acessíveis.

Mas não é isto que acontece sempre e esse problema, na verdade, vem acompanhando as pessoas da sociedade há muito tempo.

Na China, em 1911, e na Rússia, em 1917, as revoluções socialistas trouxeram para o cenário dos conflitos interesses de grupos de pessoas, envolvendo questões políticas, econômicas e sociais.Tanto na Inglaterra como na China, esses conflitos eram vistos como conflitos de interesses coletivos de pessoas determinadas.Nos Estados Unidos, em 1938, foram disciplinadas três espécies de class actions para dirimir conflitos coletivos de pessoas representadas por um único integrante da classe, ou seja, as espécies true, hybride spurious.

Foi na Itália, porém, na década iniciada em 1970, que se desenvolveu e 
ganhou destaque o estudo dos interessesdifusos, identificados pela indeterminação de seus titulares e indivisibilidade de seu objeto.

A intensidade com que se manifestavam esses interesses difusos proporcionou o surgimento, ainda que forçado, de um modo diferente de administrar o Estado.

A defesa da soberania do povo não mais era reconhecida como tarefa exclusiva do Poder Público, na medida em que grupos representativos da sociedade assumiam o comando de uma espécie de soberania social em face das demandas em massa.

E aqui, o direito à acessibilidade e a ação civil pública começam a se dar as mãos para a missão de efetivar o direito fundamental difuso do acesso aos espaços urbanos, no sentido de promover a inclusão social das pessoas com deficiência.

Atualmente, a apuração de danos morais e patrimoniais promovida por intermédio da ação civil pública disciplinada pela Lei 7.347/85, vale dizer, os objetos da ação civil pública na legislação brasileira referem-se aos seguintes direitos difusos ou coletivos:

- Direito decorrente de infração praticada contra o meio-ambiente ecologicamente equilibrado.

- Direito decorrente de infração praticada contra o consumidor.

- Direito decorrente de infração praticada contra bens e direitos de valor artístico, estético, histórico, turístico e paisagístico.

- Direito decorrente de infração praticada contra qualquer outro interesse difuso ou coletivo.

- Direito decorrente de infração praticada contra a ordem econômica.

- Direito decorrente de infração praticada contra a ordem urbanística.

- Direito decorrente de infração praticada contra a honra e a dignidade de grupos raciais, étnicos ou religiosos.

- Direito decorrente de infração praticada contra o patrimônio público e social.

Em face da vocação intervencionista do Estado Brasileiro na economia das pessoas, a Lei 7.347/85 trouxe conflitos sociais de grande abrangência e de forte peso político para a apreciação do Poder Judiciário por meio de ações coletivas que atraíram agentes até então desconhecidos para a demanda e exigiu soluções que 
ainda não haviam sido enfrentadas, ou seja, decidir reclamações sobre a gestão de uma política pública.

E cresceu de importância com a vigência do Código de Defesa do Consumidor - Lei 8.078/1990 -passando a ter por objeto a defesa de todos os interesses coletivos lato sensu, aí incluídos os difusos, os coletivos e os individuais homogêneos.

E, a gestão da política pública envolve a efetivação de direitos fundamentais da pessoa humana.

Por que podemos reconhecer o direito de acesso das pessoas com deficiência aos espaços urbanos, direito esse que está envolvido na política pública, como um DIREITO FUNDAMENTAL?

Porque as previsões que 0 asseguram preservam a dignidade dessas pessoas e o direito à vida digna é um direito fundamental.

Sendo fundamental, por que podemos nele reconhecer um DIREITO DIFUSO?

Podemos reconhecer porque, como demonstrado no Capítulo 3 acima, o direito de acesso das pessoas com deficiência aos espaços urbanos é, na medida exata do conceito incluído no inciso I do parágrafo único do artigo 81 do Código Brasileiro de Defesa do Consumidor, a Lei 8.078 de 11 de setembro de 1990, um direito transindividual, de natureza indivisível, cujos titulares são pessoas indeterminadas e ligadas por circunstância de fato.

Dando contornos finais a esta conclusão, devemos ter presente, mais uma vez, o fato de que são as disposições da ação civil pública que regem as ações de responsabilidade por danos morais e patrimoniais causados aos direito difusos, como é o direito de acesso das pessoas com deficiência aos espaços públicos.

\section{REFERÊNCIAS}

BARROSO, Luís Roberto. O novo direito constitucional brasileiro: contribuições para a construção teórica e prática da jurisdição constitucional no Brasil. Belo Horizonte: Fórum. 2013.

BRAGA, Rogério Piccino. STRASSER, Francislaine de Almeida Coimbra e SANTOS, Jurandir José dos. $O$ direito à inimputabilidade penal: o retrocesso da redução da maioridade penal.1aㅡ ed. Bandeirantes/PR: Redige Produção Editorial. 2015. 
BRASIL. Ministério das Cidades. Secretaria Nacional de Transporte e da Mobilidade. Brasília, 2015. Disponível em: http://planodiretor.mprs.mp.br/arquivos/planmob.pdf. Acesso em: 21 dez.2019

. Dados do Censo 2010 do Instituto Brasileiro de Geografia e Estatística - IBGE. Disponível em:http://7a12.ibge.gov.br/vamos-conhecer-o-brasil/nossopovo/caracteristicas-da-populacao.html. Acesso em: 21 jan. 2019

CAMBIAGHI, Silvana Serafino. Desenho universal: métodos e técnicas para arquitetos e urbanistas. São Paulo: Senac, 2007.

FIORILLO, Celso Antonio Pacheco. Curso de Direito Ambiental Brasileiro. 14를 $\mathrm{ed}$. São Paulo: Saraiva. 2013.

GUIMARÃES, Marcelo Pinto. Acessibilidade: diretriz para a inclusão. Disponível em: http:// http://www.adaptse.org/1723. Acesso em 10 jan.2019

GRINOVER, Ada Pellegrini et al. Código Brasileiro de Defesa do Consumidor comentado pelos autores do anteprojeto. $9^{\mathrm{a}}$ ed.Rio de Janeiro: Forense Universitária. 2007.

HABERMAS, Jürgen. A inclusão do outro: estudos de teoria política. São Paulo: Loyola, 2002.

LANCHOTTI, José Antonio. Critérios de desempenho da mobilidade no espaço urbano construído como avaliadores da cidade acessível: o caso de Ribeirão Preto. Tese de doutorado apresentada à Faculdade de Arquitetura e Urbanismo de São Paulo em Arquitetura:, São Paulo, 2005.

LEITE, Flávia Piva Almeida; RIBEIRO, Lauro Luiz Gomes; COSTA FILHO, Waldir Macieira da. (coord.). Comentários ao Estatuto da Pessoa com Deficiência. São Paulo: Saraiva, 2016.

MACE, Ron. The Center Universal desing. About Ron Mace.Internet: http:/www.ncsu.edu/cud/about_us/usronmace.htm . Acessado em 207/2018.

MANCUSO, Rodolfo de Camargo. Ação Civil Pública: em defesa do meio ambiente, do patrimônio cultural e dos consumidores: Lei 7.347/1985 e legislação complementar. $12^{\mathrm{a}}$ ed. - São Paulo: Editora Revista dos Tribunais. 2011.

PIVA, Rui Carvalho. Bem ambiental. São Paulo: Max Limonad. 2000.

O Instituto Brasileiro de Direito de Família e as Ações Civis Públicas. Bandeirantes/PR: Redige Produção Editorial. 2016. 